\title{
Apakah perceived usefulness dapat meningkatkan continuance intention?
}

\author{
N. Larassita, G. Razati \& S. Sulastri \\ Universitas Pendidikan Indonesia \\ nilamlarassita@upi.edu
}

\begin{abstract}
The purpose of this study is to find out the perceived usefulness and continuance intention. The design of this study was a cross sectional method. This study uses a descriptive approach with explanatory survey method. A total of 145 respondents were selected using-probability sampling. A questionnaire was used as a research instrument to collect data from respondents. The analysis technique used is descriptive technique using frequency distribution. Based on the results of the study using descriptive analysis, obtained perceived usefulness results in a good category, and good enough category for continuance intentions. The difference in this study lies in the object of the study, the time of the study, the measuring instrument, the literature used, the theory used and the results of the study.
\end{abstract}

Keywords: Continuance Intention and Perceived Usefulness

Abstrak: Tujuan penelitian ini adalah untuk mengetahui gambaran perceived usefulness dan continuance intention. Desain penelitian ini adalah cross sectional method. Penelitian ini menggunakan pendekatan deskriptif dengan metode explanatory survey. Sebanyak 145 responden dipilih dengan menggunakan probability sampling. Sebuah kuesioner digunakan sebagai instrumen penelitian untuk mengumpulkan data dari responden. Teknik analisis yang digunakan adalah teknik deskriptif dengan menggunakan distribusi frekuensi. Berdasarkan hasil penelitian menggunakan analisis deskriptif, didapatkan hasil perceived usefulness berkategori baik, dan continuance intention berkategori cukup baik. Perbedaan dalam penelitian ini terletak pada objek penelitian, waktu penelitian, alat ukur, literatur yang digunakan, teori yang digunakan dan hasil penelitian.

Kata Kunci: Continuance Intention dan Continuance Intention

\section{PENDAHULUAN}

Pemasaran sejatinya merupakan tentang identifikasi dan menemukan kebutuhan dari konsumen. Memahami dan mengatahui kebutuhan konsumen dengan baik serta tepat merupakan salah satu tujuan dari pemasaran. Hal tersebut didukung oleh Kotler \& Keller (2016) yang menyatakan bahwa konsumen memiliki peranan penting dalam siklus pemasaran oleh karena itu memahami perilaku konsumen menjadi hal yang diharuskan bagi para stakeholder. Perusahaan harus memiliki pengetahuan yang luas mengenai perilaku sasarannya agar dapat merangsang pembelian konsumen (Razati, 2008). Perilaku konsumen harus dipahami dengan benar karena, jika produk yang dikonsumsi oleh konsumen memenuhi harapan dan memberikan kesenangan serta kepuasan maka konsumen akan mengalami niat untuk membeli kembali (repurchase intention) atau berinteraksi secara terus-menerus atau berkelanjutan dengan suatu produk (continuance intention) (Kotler \& Keller, 2016). Perilaku konsumen dalam membeli barang atau jasa tercermin dalam proses pengambilan keputusan pembelian (Erisha \& Razati, 2016).

Konsep continuance intention mengacu padas istem informasi yang digunakan oleh konsumen 
pada suatu kegiatan yang sedang berlangsung secara terus menerus (Y. Lee \& Kwon, 2011) atau dapat dilihat sebagai penggunaan sistem informasi atau suatu layanan yang terus berlanjut dimana keputusan menggunakan sistem informasi secara lanjut dipengaruhi oleh keputusan awal saat menggunakan sistem informasi (Chang \& Zhu, 2012). Menurut Bhattacherjee (2001) menganggap bahwa niat kelanjutan pengguna (continuance intention) serupa dengan niat pembelian kembali konsumen (repurchase intention).

Continuance intention merupakan gambaran sejauh mana konsumen akan memutuskan untuk menggunakan suatu sistem informasi dan mengacu pada niat individu untuk terus berpartisipasi dalam kegiatan setelah sebelumnya mengadopsinya (Chen, 2015). Penelitian tentang continuance intention ini telah dilakukan pada perbankan, seperti layanan bank di smartphone dan ATM, diteliti juga pada instansi pendidikan yang menggunakan e-learning dan web perpustakaan (e-library), diteliti juga pada media sosial, e-shopping, Internet Protocol Television (IPTV, pelelangan online (online auction), dan academic virtual communities (AVCs) (Mouakket \& Bettayeb, 2015; Noorhidawati \& Ghalebandi, 2016). Melihat hasil penelitian terdahulu dapat diketahui bahwa rata-rata penelitian mengenai continuance intention dilakukan pada suatu sistem informasiatau layananberbasis online dan atau offline.

Kemajuan yang cepat dalam teknologi dirasakan dalam berbagai aspek kehidupan dan tidak terkecuali dalam aspek keuangan. Sesuai dengan hal tersebut suatu sistem layanan keuangan di Indonesia tentu harus efektif dan efisien sejalan dengan tujuan dari adanya teknologi. Transaksi ekonomi sekarang ini tidak hanya difasilitasi dengan uang kartal dan giral saja, tapi telah merambah dengan menggunakan instrumen non tunai secara elektronik yang lebih efisien dan ekonomis.

E-money adalah alat pembayaran yang memiliki nilai uang yang tersimpan secara elektronik dalam suatu media server atau chip. E- money dapat digunakan pada berbagai macam jenis pembayaran yang bekerjasama dengan penerbit $e$-money. Nilai uang dalam e-money akan berkurang pada saat konsumen menggunakannya untuk pembayaran. E-money hadir di Indonesia sejak tahun 2009. E-money diterbitkan oleh pihak perbankan dan lembaga selain bank atas perizinan dari Bank Indonesia. Data Bank Indonesia per Juli 2016 mencatat terdapat 20 penerbit $e$-money yang terdiri dari 9 bank dan 11 lembaga selain bank. Peraturan tentang $e$-money diatur dalam Peraturan Bank Indonesia Nomor 11/12/PBI/2009 tentang Uang Elektronik (Electronic Money) (antaranews.com).

Bank Indonesia saat ini sedang gencargencarnya menanamkan pemahaman mengenai cashless society kepada masyarakat Indonesia. Cashless society adalah masyarakat yang meminimalisir penggunaan uang tunai sebagai alat pembayaran atas transaksi ekonomi yang mereka lakukan. E-money merupakan salah satu solusi untuk mendukung gerakan cashless society. Walaupun $e$-money merupakan produk baru yang dikeluarkan oleh bank umum, bukan berarti masyarakat tidak tertarik akan e-money. Hal tersebut dapat dilihat dari diagram pertumbuhan transaksi beberapa produk perbankan di bawah ini:

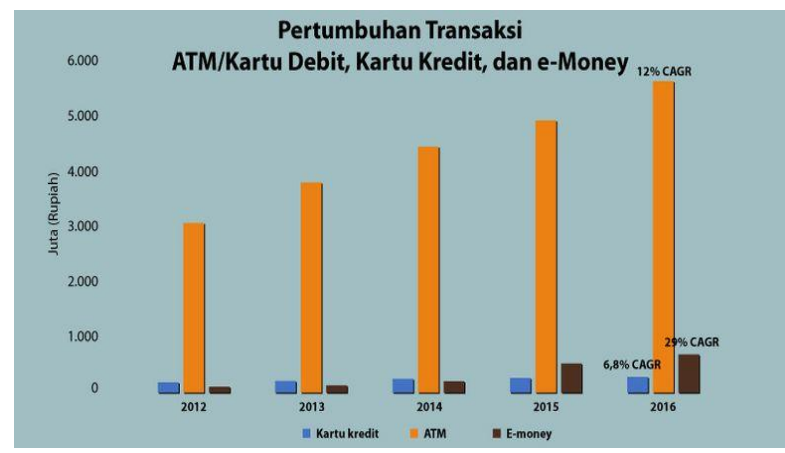

Sumber: infobanknews.com

Gambar 1 Pertumbuhan Transaksi Atm/Kartu Debit, Kartu Kredit, Dan E-Money

BerdasarkanGambar 1.2 dapat terlihat bahwa selama janka waktu lima tahun, pertumbuhan transaksi e-money terus mengalami peningkatan. Terlihat dari tahun 2012, lima tahun setelah dikeluarkannya $e$-money untuk pertama kalinya yaitu pada tahun 2007, walaupun pada tahun 2012 dan 2013 pertumbuhan transaksi $e$ money masih di bawah pertumbuhan transaksi 
kartu kredit pelan namun pasti pada tahun $2014 e$ money sudah bisa menyamakan pertumbuhan transaksinya dengan pertumbuhan kartu kredit.

Tahun 2015 e-money megalami pertumbuhan yang lebih tinggi dibandingkan dengan kartu kredit, begitu pun dengan tahun 2016 tingkat transaksi pertumbuhan $e$-money semakin tinggi.

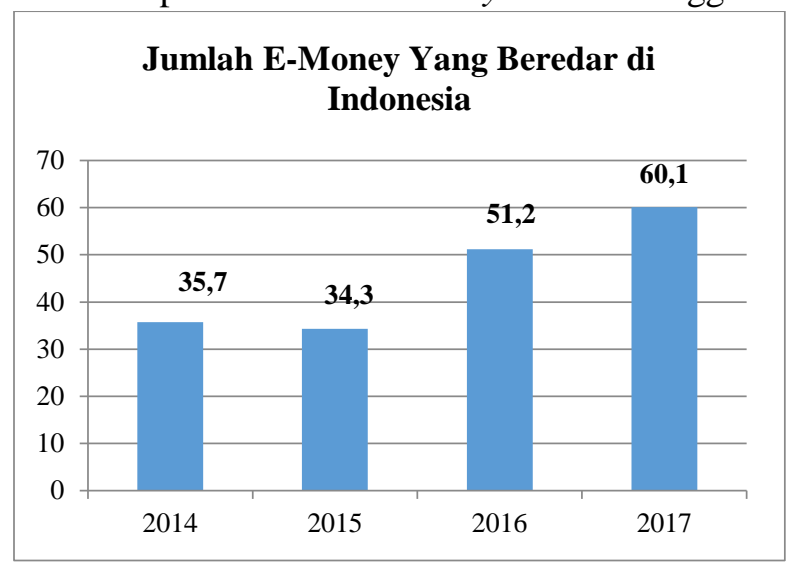

Sumber: www.bi.go.id

Gambar 2 Jumlah E-Money Yang Beredar Di Indonesia

Berdasarkan Gambar 2 dapat terlihat bahwa jumlah e-money yang beredar di masyarakat Indonesia setiap tahunnya mengalami perubahan yang fluktuatif. Tahun 2014 tercatat e-money yang beredar sebanyak 35,7 juta. Tahun 2015 terjadi penurunan jumlah e-money yang beredar sebanyak 1,4 juta menjadi 34,3 juta. Tahun2016 jumlah e-money yang beredar mengalami peningkatan sebanyak 16,9 juta dari tahun sebelumnya menjadi 51,2 juta. Dan pada tahun 2017e-money yang beredar terus mengalami peningkatan tercatat sebanyak 8,9 juta dari tahun sebelumnya menjadi 60,1 juta.

Perbankan yang mengeluarkan produk $e$ money di Indonesia tercatat sudah cukup banyak. Hal ini terlihat pada tahun 2016 terdapat 9 bank yang sudah mempunyai produk e-money, diantaranya 4 bank milik negara dan 5 bank milik swasta. Bank milik negara yang sudah mempunyai produk e-money card based diantaranya adalah BCA dengan produk e-money nya yang bernama Flazz, Bank Mandiri dengan produknya yang tetap bernama e-money, BNI dengan produknya yang bernama Tapcash, dan
BRI dengan produk e-money nya yang bernama Brizzi.

Tabel 1 Jumlah Pengguna E-Money Berdasarkan Bank

\begin{tabular}{|c|c|c|c|c|c|c|c|}
\hline $\begin{array}{c}\text { Electronice } \\
\text { Moneyf }\end{array}$ & 2014 & $\begin{array}{l}\text { aser- } \\
\text { ano }\end{array}$ & $2015 \square$ & $\begin{array}{l}\text { asee } \\
\text { ano }\end{array}$ & 2016a & $\begin{array}{l}\text { Persentases } \\
\text { Kenaikano }\end{array}$ & 2017 \\
\hline & 5.000 .0 & $24,2 \%$ & 10 & $33 \% 0$ & 8 & $30,99 \%$ & 10.8 \\
\hline & 6.400 .0000 & $35,9 \%$ & 8.700 .0000 & $9,1 \%$ & 9.500 .000 & $10 \%$ & 13.500 .0000 \\
\hline & 450.0000 & $2,2 \%$ & 5.500 .000 & $30 \%$ & 7.150 .0 & $11,88 \% 00$ & 8.000 .0000 \\
\hline $\begin{array}{c}\text { TapCash } \\
\text { (BNI)o }\end{array}$ & 250.00 & $20 \%$ & 500.00 & $30,2 \%$ & 400.00 & $0,13 \%$ & 2.100 .0 \\
\hline
\end{tabular}

Sumber: infobanknews.com

Berdasarkan Tabel 1 dapat terlihat bahwa presentase kenaikanpengguna $e$-money dari setiap Bank sangat fluktuatif. Dapat dilihat dari tabel di atas bahwa peningkatan terendah pengguna $e$ money dari tahun 2016 sampai dengan tahun 2017 adalah Brizzi BRI yang mengalami penurunan pesentase kenaikan pengguna selama 2 tahun berturut-turut. Sedangkan, persentase peningkatan pengguna e-money tertinggi yaitu Flazz BCA dengan peningkatan pengguna sebanyak 33\% dari tahun 2016 menjadi 42,10\% pengguna pada tahun 2017. Rendahnya penggunaan Brizzi mengindikasikan bahwa continuance intention perusahaan menurun.

Penurunan continuance intention ini harus diperhatikan karena permasalahan terbesar bagi perusahaan yang bergerak di bidang tekonologi adalah tidak terjadinya proses adaptasi atau penerimaan teknologi dengan baik oleh konsumen atau bahkan gagal dalam menerima teknologi tersebut. Beberapa faktor yang dapat mempengaruhi itu antara lain kurang bermanfaatnya suatu teknologi, sulit digunakan, tidak efektif dan efisien. Hal ini berdampak pada niat konsumen untuk menggunakan suatu layanan tersebut secara berkelanjutan atau tidak, apabila konsumen tidak menggunakan kembali layanan tersebut maka dengan kata lain pembelian produk atau jasa menurun dan mengakibatkan pada berkurangnya pendapatan perusahaan (Kotler \& Armstrong, 2014).

Beberapa alasan yang menyebabkan masyarakat Indonesia memiliki continuance intention yang rendah terhadap e-money sehingga enggan bertransaksi menggunakan e-money diantaranya karena belum adanya standarisasi 
uang elektronik. Hal ini menyebabkan sulitnya interoperability antar penerbit uang elektronik di Indonesia, maksudnya mesin EDC (Electronic Data Capture) belum bisa dipakai oleh semua produk e-money yang berasal dari Bank yang berbeda dan kurangnya edukasi serta sosialisasi tentang produk.

Permasalahan di atas dapat terjadi pada produk e-money dari setiap Bank dan tidak terkecuali BRI yang mengalami penurunan dalam persentase peningkatan pengguna selama tahun 2016 dan 2017. Mengingat Brizzi BRI sudah meluncurkan e-money pada tahun 2012 dengan jumlah kartu sebanyak 745 kartu. Hal ini menjadi masalah yang serius karena pertumbuhan pengguna Brizzi pada tahun 2016-2017 rendah hanya sebesar $11,88 \%$ pengguna berbeda halnya dengan pertumbuhan pengguna Brizzi pada tahun 2014 sampai dengan 2015, yaitu sebesar 112,2\% pengguna.

Perusahaan yang bergerak di bidang sistem informasi atau layanan perlu meningkatkan continuance intention karena biaya pengembangan untuk pengguna yang baru dianggap lebih tinggi dalam lingkungan online dibandingkan melalui saluran tradisional. Keuntungan dalam menggunakan suatu layanan dapat tumbuh lebih cepat setelah pengguna sudah pernah menggunakan suatu layanan sebelumnya. Karena pelanggan online yang sebelumnya sudah pernah berinteraksi atau menggunakan suatu layanan cenderung akan menghabiskan lebih banyak waktu dan uang daripada saat mereka pertama kali berinteraksi atau menggunakan suatu layanan (Reichheld \& Schefter, 2000 dalam jurnal (Hou, 2016).

Hasil dari peneliti terdahulu mengatakan bahwa continuence intention dipengaruhi oleh faktor kognitif dan faktor afektif. Faktor kognitif, seperti mempunyai rasa kegunaan atau manfaat (perceived usefulness) (Gao \& Bai, 2014), mudah digunakan (ease of usage) (Hu \& Zhang, 2016), kepuasan (satisfaction) (Ju et al., 2017), kepercayaan (trust) (Susanto et al., 2016) dan faktor afektif, seperti kebiasaan dan intesitas yang tinggi dalam menggunakan layanan tersebut, keamananan (security) dan self efficiacy (Lwoga \& Komba, 2015). Bhattacherjee (2001) mengemukakan bahwa faktor perceived usefulness, perceived ease of usage, satisfaction, dan confirmation, memiliki pengaruh positif pada continuance intention.

Penelitian lain mengenai pengaruh perceived usefulness, perceived ease of usage, perceived risk, trust dan attitude toward using terhadap continuance intention pada internet banking, mobile banking, dan e-banking lainnya menunjukan bahwa terdapat pengaruh positif perceived usefulness terhadap continuance intention (Bangkara dkk, 2016). Berdasarkan penelitian beberapa ahli terdapat faktor yang berpengaruh terhadap continuance intention yaitu perceived usefulness. Pengaruh perceived usefulness terhadap continuance intention ebanking berdampak positif dikarenakan dengan manfaat yang dirasakan oleh pengguna dalam melakukan transaksi dengan e-money maka pengguna akan bersikap positif untuk menggunakan teknologi tersebut secara berkelanjutan atau terus-menerus (Gao \& Bai, 2014).

Perceived usefulness merupakan salah satu variabel yang dapat meningkatkan continuance intention. Perceived usefulness berpengaruh positif untuk meningkatkan customer continuance intention hal ini dibuktikan oleh penelitian sebelumnya yang meneliti faktor apa yang menghantarkan konsumen untuk melakukan transaksi padae-banking dan e-shopping (Joo \& Choi, 2016). Perceived usefulness merupakan faktor yang mempunyai dampak yang luas bagi keberlangsungan suatu layanan yang dapat dikemas sedemikian rupa sehingga layanan yang ditawarkan memiliki nilai yang lebih bagi penggunanya dan dapat membuat penggunanya menggunakan layanan tersebut secara berkelanjutan (Zhang, 2017).

Menurut beberapa ulasan dari media massa eletronik Brizzi hadir dengan memberikan berbagai kebermanfaatan bagi konsumen, baik dalam effectiveness dan efficiency selaku dua indikator dariperceived usefulness yang 
menunjukkan keberhasilan bagi produk e-money. Strategi atau tidakan yang sudah dilakukan Brizzi yang sesuai dengan indikator efficiency, yaitu memudahkan pengguna Brizzi dalam mengisi ulang e-money mereka karena Brizzi dapat di Top Up atau diisi ulang melalui seluruh e-Channel BRI (ATM, SMS Banking BRI, Internet Banking BRI), dan di mesin EDC Brizzi yang terdapat di merchant-merchant kerjasama Brizi, baik menggunakan kartu debit BRI maupun kartu debit Bank manapun di Indonesia yang tergabung di jaringan ATM Bersama maupun ATM Prima dan jaringan ATM Link.

Selain itu Brizzi memudahkan pengguna untuk melakukan transaksi dalam pemenuhan kebutuhan sehari-hari mereka, sesuai dengan indikator effectivenes, yaitu Brizzi dapat digunakan sebagai media pembayaran atau transaksi kebutuhan sehari-hari di berbagai merchant seperti Carrefour, Hypermart, Indomaret, Lawson, Alfamart, foodcourt, SPBU, jasa transportasi, pembayaran Toll, sebagai alat pembayaran parkir ISS, pembayaran sarana public airport tax, dan resto.

Perusahaan yang bergerak pada bidang sistem informasi seperti perbankan dapat mengimplementasikan perceived usefulness dalam setiap produk. Perceived usefulness merupakan sejauh mana pengguna percaya bahwa menggunakan sistem tertentu akan meningkatkan kinerja mereka dimana di dalam kinerja terdapat keefektifan dan keefisiensian. Perusahaan harus memberikan manfaat pada produk yang mereka keluarkan bagi konsumen, bukan hanya tentang bagaimana perusahaan ingin konsumen membeli saja.

Berdasarkan latar belakang yang penelitian yang telah diuraikan untuk mengetahui apakah perceived usefulness yang dilakukan pada electronic money Bank X di Indonesia berhasil atau tidak, maka peneliti perlu melakukan penelitian dengan judul "Pengaruh Perceived Usefulness terhadap Continuance Intention" (Survei pada pengguna electronic money Bank X).

Berdasarkan latar belakang dan identifikasi masalah di atas, maka didapat rumusan masalah sebagai berikut: 1) bagaimana gambaran perceived usefulness pada electronic money, 2) bagaimana gambaran continuance intention pada electronic money, dan 3) seberapa besar pengaruh perceived usefulness terhadap continuance intention pada electronic money.

Tujuan dilakukannya pen (Razati \& Ruhimat, 28)elitian ini adalah untuk memberikan bukti empiris mengenai pengaruh perceived usefulness terhadap customer continuance intention, yang dijabarkan sebagai berikut: 1) untuk memperoleh gambaran perceived usefulness, 2) untuk memperoleh gambaran continuance intention, 3) untuk memperoleh besarnya pengaruh perceived usefulness terhadap continuance intention.

\section{METODE PENELITIAN}

Metode yang digunakan dalam penelitian ini adalah explanatory survey. Explanatory survey dilakukan untuk mengeksplorasi situasi masalah, yaitu untuk mendapatkan ide-ide dan wawasan kedalam masalah yang dihadapi manajemen atau para peneliti tersebut (Maholtra, 2010:96).

Jenis data yang digunakan dalam penelitian ini adalah data primer dan data sekunder. Menurut Kuntjojo (2009:34) data primer, adalah data yang diperoleh langsung pihak yang diperlukan datanya dan data sekunder, merupakan data yang tidak diperoleh langsung dari pihak yang diperlukan datanya. Menurut Hasibuan (2007:46) data primer yang berasal dari hasil-hasil penelitian seperti jurnal, thesis, disertasi dan lain sebagainya yang digunakan untuk memantapkan ide yang telah kita temukan sebelumnya. Selain itu juga bisa didukung dari sumber data sekunder seperti buku, majalah, koran, penelusuran dengan komputer (online database) dan lain sebagainya karena sumber-sumber tersebut memberikan gambaran dan ide yang lebih luas tentang topik yang ingin kita kaji.

Teknik pengumpulan data mengacu pada cara apa yang perlu dilakukan dalam penelitian agar dapat memperoleh data. Teknik pengumpulan data dapat dibedakan menjadi dua, yaitu dengan teknik tes dan non tes. Teknik non tes, yaitu dengan tidak memberikan soal-soal atau tugas- 
tugas kepada subjek yang diperlukan datanya. Dalam teknik non tes, data dari subjek penelitian dikumpulkan dengan wawancara, kuesioner, observasi, dan pencatatan dokumen (Kuntjojo, 2009). Penelitian ini memperoleh data dengan menggunakan teknik teknik non tes yaitu studi kepustakaan yaitu pengumpulan data sekunder dengan mempelajari literatur kepustakaan seperti buku, jurnal, majalah, website, dan dokumen lembaga yang berkaitan dengan teori atau konsep masalah penelitian, Angket (kuesioner), yaitu teknik pengumpulan data melalui penyebaran seperangkat daftar.

Analisis deskriptif merupakan bentuk analisis data untuk menguji generalisasi hasil penelitian yang didasarkan atas satu sampel. Analisis deskriptif ini dilakukan melalui pengujian hipotesis deskriptif. Analisis data verifikatif dilakukan untuk menguji hipotesis dengan menggunakan uji statistik dan menitik beratkan pada pengungkapan perilaku variabel penelitian.

Teknik analisis data yang dipergunakan untuk mengetahui hubungan korelatif dalam penelitian ini yaitu teknik analisis regresi sederhana (regresi linear) sederhana karena penelitian ini menganalisis dua variabel. Analisis regresi linear sederhana merupakan hubungan secara linear antara satu variabel independen dengan variabel dependen.

Analisis ini dilakukan untuk mengetahui arah hubungan antara variabel perceived usefulness (independen) dengan variabel continuance intention (dependen) apakah positif atau negatif serta untuk memprediksi nilai variabel apabila nilai variabel independen mengalami penurunan atau kenaikan.

\section{HASIL DAN PEMBAHASAN}

Uji normalitas dilakukan dengan tujuan untuk mengetahui apakah data yang digunakan berdistribusi normal atau tidak, sehingga data tersebut dapat digunakan atau tidak dalam model analisis jalur. Uji normalitas pada penelitian ini menggunakan rumus Kolmogrov-Smirnov dengan bantuan software SPSS 22,0 for windows dengan hasil seperti Tabel 1 berikut:
Tabel 1. Uji Kolmogrov Smirnov One-Sample Kolmogorov-Smirnov Test

Unstandardized Residual

\begin{tabular}{lll}
\hline $\mathrm{N}$ & & \multicolumn{1}{l}{145} \\
\hline Normal Parameters & Mean &, 0000000 \\
\cline { 2 - 3 } & $\begin{array}{l}\text { Std. } \\
\text { Deviation }\end{array}$ & 3,41599187 \\
\hline Most Extreme Differences & Absolute &, 064 \\
\cline { 2 - 3 } & Positive &, 064 \\
\cline { 2 - 3 } & Negative &,- 046 \\
\hline Test Statistic & &, 064 \\
\hline Asymp. Sig. (2-tailed) & &, $200^{\text {c,d }}$ \\
\hline
\end{tabular}

Sumber: Hasil Pengolahan Data 2018

Berdasarkan Tabel 1 menunjukan bahwa dari hasil uji normalitas dengan Kolmogorov-Smirnof Test diperoleh nilai signifikansi adalah 0,200 sementara kriteria data dikatakan normal apabila nilai signifikasinya lebih dari 0,05. Maka dapat disimpulkan data tersebut berdistribusi normal

Langkah selanjutnya dalam penelitian ini adalah perlunya mengetahui apakah kedua variabel perceived usefulness atas continuance intention benar-benar memiliki hubungan linear atau tidak. Untuk itu perlu dilakukannya uji linearitas regresi variabel tersebut. Pengujian linearitas ini bertujuan untuk mengetahui hubungan linearitas antar variabel perceived usefulness atas continuance intention. Hasil analisis linearitas tersebut dapat disajikan pada Tabel 2 berikut ini

Tabel 2 Hasil Uji Linearitas ANOVA Table

\begin{tabular}{|c|c|c|c|c|c|}
\hline & & $\begin{array}{l}\text { Sum of } \\
\text { Squares }\end{array}$ & & $\begin{array}{l}\text { Mean } \\
\text { SquareF }\end{array}$ & Sig. \\
\hline Continuanc & eBetween(Combine & l) 444,042 & 18 & \multicolumn{2}{|c|}{$24,6692,397,003$} \\
\hline Intention * & Groups Linearity & 60,657 & 1 & \multirow{2}{*}{\multicolumn{2}{|c|}{$60,6575,893,017$}} \\
\hline Perceived & Deviation & & & & \\
\hline Usefulness & $\begin{array}{l}\text { from } \\
\text { Linearity }\end{array}$ & 383,385 & 17 & \multicolumn{2}{|c|}{$22,5522,191,007$} \\
\hline & Within Groups & 1296,951 & 1126 & \multicolumn{2}{|l|}{610,293} \\
\hline & Total & 1740,993 & \multicolumn{3}{|c|}{144} \\
\hline
\end{tabular}

Sumber: Hasil Pengolahan Data 2018

Berdasarkan hasil pengujian menggunakan uji

$F_{\text {tabel}}$, didapatkan $F_{\text {hitung }}$ sebesar 2, 191 dengan $F_{\text {tabel }}$ 3,91 maka dapat dilihat bahwa $F_{\text {hitung }} \leq F_{\text {tabel }}$ artinya 
variabel perceived usefulness (X) secara keseluruhan model tersebut sudah fit serta terdapat hubungan antara variabel perceived usefulness terhadap continuance intention sehingga regresi bisa dipakai untuk meprediksi continuance intention pengguna. Berdasarkan hasil pengujian linearitas, maka dapat dikatakan bahwa data yang dihasilkan memenuhi asumsi linearitas.

\section{Tabel 3 Model Regresi Sederhana}

Coefficients $^{\mathrm{a}}$

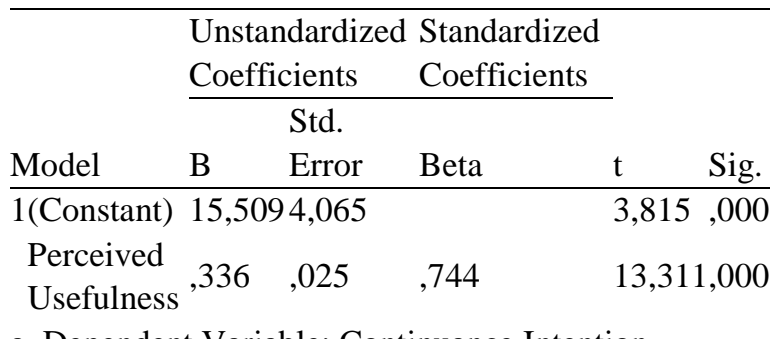

a. Dependent Variable: Continuance Intention

Sumber: Hasil Pengolahan Data 2018

Berdasarkan Tabel 3 pada kolo B, tercantum nilai konstanta dan nilai koefisien regresi linear sederhana untuk variabel bebas. Dari nilai-nilai tersebut maka dapat ditemukan mode regresi linear sederhana yang dinyatakan dalam bentuk persamaan sebagai berikut:

$$
\begin{aligned}
& Y=a+b X \\
& Y=15,509+0,744 X
\end{aligned}
$$

Berdasarkan persamaan regresi linear di atas, nilai konstanta dan nilai koefisien regresi linear sederhana untuk variabel bebas. nilai konstanta sebesar 15,509 menyatakan bahwa jika tidak ada perceived usefulness, maka besarnya continuance intention sebesar 15,509. Koefisien regresi pada variabel perceived usefulness adalah 0, 744 yang artinya setiap terjadi penambahan-penambahan nilai perceived usefulness akan terjadi peningkatan continuance intention sebesar 0,744 . Sebaliknya jika terjadi penurunan continuance intention sebesar 0,744 satu-satuan nilai. Maka dapat dikatakan bahwa perceived usefulness yang dibangun oleh perusahaan akan berpengaruh terhadap tingkat penggunaan konsumen.

Hipotesis penelitian ini adalah perceived usefulness terhadap continuance intention. Hipotesis ini diuji dengan menggunakan SPSS 22.0 for windows.

\section{Tabel 4 Hasil Perhitungan Uji T}

\begin{tabular}{|c|c|c|c|c|c|}
\hline \multirow[b]{2}{*}{ Model } & \multicolumn{2}{|c|}{$\begin{array}{l}\text { Unstandardized } \\
\text { Coefficients }\end{array}$} & $\begin{array}{l}\text { Standardized } \\
\text { Coefficients }\end{array}$ & \multirow[b]{2}{*}{$\mathrm{T}$} & \multirow[b]{2}{*}{ Sig. } \\
\hline & B & $\begin{array}{l}\text { Std. } \\
\text { Error }\end{array}$ & Beta & & \\
\hline 1 (Constant) & 15,509 & 4,065 & & 3,815 & ,000 \\
\hline $\begin{array}{l}\text { Perceived } \\
\text { Usefulness }\end{array}$ & ,336 & ,025 & ,744 & 13,31 & 1,000 \\
\hline
\end{tabular}

Coefficients

a. Dependent Variable: Continuance Intention

Sumber: Hasil Pengolahan Data 2018

Pada Tabel 4 dapat diketahui besarnya $t_{\text {hitung }}$ adalah 13,311 dengan $t_{\text {tabel }} 1,655$ sehingga $t_{\text {hitung }}>$ $t_{\text {tabel }}(13,311>1,655)$ maka keputusan yang dapat diambil adalah $\mathrm{H}_{0}$ ditolak dan $\mathrm{Ha}$ diterima. Artinya perceived usefulness berpengaruh terhadap continuance intention.

Analisis koefisien determinasi ( $\mathrm{R}$ square) bertujuan untuk mengetahui seberapa besar kemampuan variabel independen (X) terhadap variabel dependen (Y). Hasil uji determinasi yang telah dilakukan adalah sebagai berikut.

\section{Tabel 5 Koefisien Determinasi Dari Perceived Usefulness Terhadap Continuance Intention}

Model Summary ${ }^{\mathrm{b}}$

\begin{tabular}{llll}
\hline ModelR & $\begin{array}{l}\mathrm{R} \\
\text { Square }\end{array}$ & $\begin{array}{l}\text { Adjusted R } \\
\text { Square }\end{array}$ & $\begin{array}{l}\text { Std. Error of the } \\
\text { Estimate }\end{array}$ \\
\hline $1 \quad, 744^{\mathrm{a}}, 553$ &, 550 & 3,365
\end{tabular}

Sumber: Hasil Pengolahan Data 2018

Pada Tabel 5 model summary output SPSS 22.0 for windows, dapat diketahui bahwa korelasi atau hubungan antara perceived usefulness dengan continuance intention memperoleh hasil sebesar 0,774 (positif). Sesuai dengan pedoman untuk memberikan interpretasi terhadap koefisien korelasi (Sugiyono 2013:95), maka korelasi antara perceived usefulness terhadap continuance intention termasuk ke dalam kategori kuat yaitu berada pada interpretasi koefisien korelasi $(0,60-$ $0,79,99)$ dengan Standar Error of Estimate (SEE) sebesar 3,365.

Untuk mengetahui besarnya presentase pengaruh perceived usefulness terhadap continuance intention, maka digunakan rumus koefisien determinasi. Besarnya nilai korelasi atau hubungan ( $\mathrm{R}$ square) yaitu sebesar 0,744. Dari output tersebut diperoleh koefisien determinasi ( $R$ 
square) sebesar 55,35\%. Sedangkan 44,65 \% sisanya dipengaruhi oleh faktor-faktor lainnya di luar perceived usefulness.

Dari output spss di atas maka dapat di simpulkan bahwa jika nilai probabilitas (Sig) penelitian < 0,05. Pada hasil di atas maka dinyatakan perceived usefulness berpengaruh signifikan terhadap continuance intention.

Perceived usefulness adalah tolak ukur untuk menilai penerimaan pada teknologi dan untuk mengukur kesuksesan atau keberhasilan teknologi tersebut (Al-Suqri, 2014; Alsabawy et al., 2016). Terdapat beberapa dimensi penting dari perceived usefulness, menurut Segars \& Grover (2015) yang menyatakan bahwa dimensi perceived usefulness terdiri dari work more quckly, job performance, increase productivity, effectiveness, makes job easier, dan useful.

Dimensi work more quickly, yang berkaitan dengan mempercepat pekerjaan pengguna adalah variabel perceived usefulness pertama yang dijadikan dasar konsumen dalam menggunakan $e$ money, work more quickly ini berkaitan dengan kecepatan dalam melakukan pekerjaan pengguna (Segars \& Grover, 2015).

Job performance didefinisikan secara luas sebagai hasil yang dicapai oleh seseorang menurut ukuran yang berlaku untuk pekerjaan yang bersangkutan (Segars \& Grover, 2015). Increase productivity, penggunaan suatu sistem oleh individu dapat meningkatkan produtivitas (Segars \& Grover, 2015). Makes job easier, penggunaan suatu sistem memudahkan pekerjaan bagi penggunanya (Segars \& Grover, 2015).

Effectivenes didefinisikan secara dimensi yang mengukur tingkat bahwa pengguna merasa teknologi atau sistem informasi dapat membantu mereka dalam mendapatkan hal yang benar untuk dilakukan (Yeh \& Teng, 2012). Useful, didefinisikan sebagai Penggunaan suatu sistem dirasakan kebermanfaatannya bagi pengguna (Segars \& Grover, 2015).

Berdasarkan hasil pengolahan data yang dilakukan melalui penyebaran angket pada konsumen yang pernah menggunakan Brizzi BRI, Perceived usefulness dapat diukur melalui perhitungan rata-rata dimensi dan perhitungan skor keseluruhan. Berikut ini dipaparkan hasil dari rekapitulasi perhitungan skor.

Tabel 6 Rekapitulasi Tanggapan Konsumen terhadap Perceived Usefulness

\begin{tabular}{lllll}
\hline No & Dimensi & $\begin{array}{l}\text { Skor } \\
\text { Total }\end{array}$ & $\begin{array}{l}\text { Skor } \\
\text { Rata-rata }\end{array}$ & $\begin{array}{l}\text { Perse } \\
\text { ntase } \\
\%\end{array}$ \\
\hline 1 & $\begin{array}{l}\text { Work more } \\
\text { quickly }\end{array}$ & 3.605 & 901,25 & 22,44 \\
2 & $\begin{array}{l}\text { Job } \\
\text { performance }\end{array}$ & 2.665 & 888,33 & 16,59 \\
3 & $\begin{array}{l}\text { Increase } \\
\text { productivity }\end{array}$ & 1.794 & 897 & 11,17 \\
4 & $\begin{array}{l}\text { Effectiveness } \\
5\end{array}$ & 1.811 & 905,5 & 11,27 \\
6 & $\begin{array}{l}\text { Makes job } \\
\text { easier }\end{array}$ & 3.589 & 897,25 & 22,34 \\
\hline Total & Useful & 2.600 & 866,6 & 16,19 \\
\hline
\end{tabular}

Sumber: Hasil Pengolahan Data 2018

Tabel 6 menunjukan bahwa perceived usefulness secara keseluruhan memperoleh skor 16.064 yang artinya sebagai besar responden menyatakan bahwa perusahaan memiliki perceived usefulness yang baik di mata konsumen. Rekapitulasi tanggapan konsumen mengenai perceived usefulness diperoleh hasil pengolahan data yang telah dilakukan melalui penyebaran 145 responden yang pernah menggunakan Brizzi. Jika dilihat berdasarkan dimensi, hasil temuan data berdasarkan Tabel 2 menunjukan bahwa yang memperoleh nilai tertinggi adalah dimensi work more quickly dengan persentase $22,44 \%$. Sementara itu dimensi paling rendah adalah dimensi increase productivity dengan persentase $11,17 \%$.

Apabila dilihat dari tabel di atas, dimensi work more quickly memperoleh nilai tertinggi, Transaksi menggunakan e-money Brizzi yang menghemat waktu menjadi alasan mengapa work more quickly memperoleh skor tertinggi. Transaksi pembayaran menggunakan Brizzi jauh lebih cepat dibandingkan dengan uang tunai, karena dapat memangkas waktu saat mencari uang tunai yang pas sesuai total pembayaran dan menghilangkan waktu saat harus menunggu kembalian tentu banyak mengehemat waktu bagi konsumen. Sedangkan, dimensi increase 
productivity memperoleh nilai terendah dikarenakan keterbatasan Brizzi dalam penggunaannya yang tidak meningkatkan produktivitas penggunanya.

Hal ini sesuai dengan penelitian terdahulu yang dilakukan oleh Adams tahun 2015 mengenai Re-Examinig Perceived Ease of Use and Usefulness: A Confirmatory Factor Analisys dimana mengkaji ulang mengenai dua faktor yang dikemukan oleh Davis (1989) yang mempengaruhi dalam penggunaan suatu teknologi yaitu faktor perceived usefulness dan ease of usage, dalam penelitian tersebut peneliti mengeluarkan indikator-indikator dari dua faktor tersebut dimana work more quickly dan effectiveness menjadi indikator yang paling sesuai untuk memprediksi perceived usefulness pada masa yang akan datang.

Berdasarkan hasil pengolahan data yang telah dilakukan melalui penyebaran kuesioner pada pengguna Brizzi, dapat diukur melalui perhitungan skor dimensi dari perceived usefulness. Skor total perceived usefulness sebesar 16.064 dengan skor ideal yaitu 18.270 perbandingan ini menunjukan gambaran perceived usefulness berada pada kategori tinggi. Dengan demikian dapat disimpulkan bahwa pengguna Brizzi menilai perceived usefulness yang dimiliki Brizzi sudah menunjukan kinerja yang diharapkan walaupun belum optimal.

Secara ideal skor yang diharapkan untuk jawaban pengguna Brizzi BRI di Indonesia terhadap pertanyaan no 1 sampai dengan 18 adalah 16.064. Dari perhitungan di atas menunjukan nilai yang diperoleh adalah sebesar 16.064 atau $87,92 \%$ dari skor ideal yaitu 18.270, dengan demikian perceived usefulness berada pada kategori tinggi.

Variabel dari continuance intention terdiri dari dua dimensi yaitu possibility of repurchase yang berkaitan dengan kemungkinan atau peluang penggunaan kembali Brizzi oleh konsumen dan times of repurchase berkaitan dengan frekuensi sebarapa sering konsumen melakukan transaksi pembayaran menggunakan Brizzi (Hu \& Zhang, 2016).
Berdasarkan hasil pengolahan data yang dilakukan melalui penyebaran kuesioner pada pengguna, continuance intention dapat diukur melalui perhitungan rata-rata dimensi dan perhitungan skor keseluruhan. Berikut ini merupakan hasil dari rekapitulasi perhitungan skor:

Tabel 3 Rekapitulasi Tanggapan Konsumen terhadap Continuance Intention

\begin{tabular}{lllll}
\hline No & Dimensi & $\begin{array}{l}\text { Skor } \\
\text { Total }\end{array}$ & $\begin{array}{l}\text { Skor } \\
\text { Rata- } \\
\text { rata }\end{array}$ & $\begin{array}{l}\text { Persentase } \\
\%\end{array}$ \\
\hline 1 & $\begin{array}{l}\text { Possibility } \\
\text { of } \\
\text { repurchase }\end{array}$ & 3.017 & 754,25 & 50,29 \\
2 & $\begin{array}{l}\text { Times of } \\
\text { repurcahse }\end{array}$ & 2.982 & 745,5 & 50,08 \\
Total & & 5.999 & $1.499,7$ & 100 \\
\hline
\end{tabular}

Sumber: Hasil Pengolahan Data 2018

Berdasarkan tabel 3 menunjukan hasil pengolahan data yang telah dilakukan melalui penyebaran 145 responden, menunjukan bahwa dimensi yang memperoleh skor tertinggi adalah dimensi possibility of repurchase dengan nilai 3.017 atau persentase sebesar 50,29\%. Sedangkan, dimensi dengan peroleh skor terendah adalah dimensi times of repurchase dengan nilai 2.982 atau persentase sebesar 50,08\%.

Dimensi possibility of repurchase menjadi dimensi dengan jumlah tertinggi dikarenakan Brizzi memiliki peluang untuk digunakan kembali dalam transaksi pembayaran e-toll Hal tersebut terjadi dikarenakan sejalan dengan peraturan yang dibuat pemerintah yang mewajibkan penggunaan electronic money sebagai alat pembayaran pada transaksi tol jadi, kemungkinan menggunakan Brizzi pada tol lebih tinggi dibandingkan kemungkinanan menggunakan pada transaksi pembayaran lainnya karena ada sisi keharusan dalam menggunakannya.

Sementara waktu saat konsumen menggunakan Brizzi yang berbeda-beda menjadi dimensi times of repurchase sebagai dimensi dengan perolehan terendah. Waktu penggunaan Brizzi itu disesuaikan dengan kebutuhan dan waktu yang dimiliki oleh konsumen itu sendiri. 
Secara keseluruhan diperoleh skor 5.999 yang artinya sebagaian besar responden merasa kebermanfaatan Brizzi sebagai alat pengganti uang tunai dalam berbagai transaksi pembayaraan yang karena kebermanfaatannya konsumen ingin menggunakan kembali Brizzi.

Berdasarkan hasil pengolahan data yang telah dilakukan, diperoleh informasi bahwa skor kinerja continuance intention menurut tanggapan dari 145 responden adalah $73,87 \%$. Secara ideal skor yang diharapkan untuk jawaban pengguna Brizzi BRI di Indonesia terhadap pertanyaan no 19 sampai dengan 26 adalah 5.999. Dari perhitungan di atas menunjukan nilai yang diperoleh adalah sebesar 5.999 atau $73,87 \%$ dari skor ideal yaitu 8.120, dengan demikian continuance intention berada pada kategori cukup tinggi.

Dengan hasil perolehan nilai tersebut, dapat disimpulkan bahwa electronic money dalam segi kinerja continuance intention sudah menunjukan kinerja yang diharapkan walau belum optimal. Hal ini sejalan dengan penelitian terdahulu yang mengungkapkan bahwa perusahaan harus memahami perilaku konsumen karena perilaku konsumen merupakan proses yang berkelanjutan, tidak terhenti pada tahapan konsumsi saja tapi terus berlanjut hingga tahapan pasca konsumsi di mana, konsumen akan memiliki dua bentuk perilaku yaitu, niat melakukan pembelian ulang atau menggunakan secara berkelanjutan apabila merasakan kepuasan atau niat tidak melakukan pembelian ulang atau menggunakan secara berkelanjutan karena mengalami ketidakpuasan (Solomon, 2007:6-7).

\section{KESIMPULAN DAN SARAN}

Berdasarkan uraian teori dan hasil penelitian yang telah dilakukan dengan menggunakan analisis deskriptif dan verifikatif menggunakan regresi linear sederhana antara perceived usefulness terhadapa continuance intention (survei pada pengguna Brizzi BRI di Indonesia) maka dapat diambil kesimpulan sebagai berikut.

Gambaran mengenai penerapan perceived usefulness yang dilaksanakan oleh Brizzi BRI di Indonesia dinilai oleh sebagaian konsumen termasuk pada kategori yang tinggi. Hal ini menunjukan bahwa penerapan perceived usefulness telah diciptakan dan dilaksanakan dengan baik oleh Brizzi BRI di Indonesia. Work more quickly merupakan dimensi tertinggi yang mendorong konsumen melakukan continuance intention pada Brizzi. Sedangkan, dimensi yang memiliki penilaian terendah dalam mempengaruhi continuance intention adalah increase productiviy dalam penggunaan Brizzi.

Gambaran dari continuance intention diukut berdasarkan beberapa dimensi seperti possibility of repurchase dan times of repurchase. Dimensi yang memiliki penilaian paling tinggi yang mempengaruhi continuance intention penggunaan Brizzi BRI di Indonesia adalah dimensi possibility of repurchase. Hal ini terjadi karena pengguna Brizzi selalu mempunyai kemungkinan atau peluang untuk bertransaksi menggunakan Brizzi. Sedangkan, dimensi dengan peniaian terendah yaitu times of repurchase karena setiap pengguna memiliki frekuensi waktu yang berbeda-beda saat mengguna Brizzi.

Perceived usefulness memiliki pengaruh terhadap continuance intention penggunaan Brizzi di Indonesia. Tingkat korelasi yang dihasilkan cukup tinggi atau cukup kuat. Hal ini menunjukkan bahwa semakin baik perceived usefulness yang diciptakan Brizzi, maka akan semakin baik pula continuance intention dalam penggunaan Brizzi.

Berdasarkan hasil penelitain yang telah dilakukan terkait pengaruh perceived usefulness terhadapa continuance intention, maka penulis merekomendasikan beberapa hal sebagai berikut:

Penerapan perceived usefulness yang telah dilakukan Brizzi BRI di Indonesia memiliki pengaruh yang secara keseluruhan bersifat signifikan dan dapat dikategorikan memiliki pengaruh yang baik terhadap continuance intention pengguna Brizzi BRI di Indonesia. Namun, terdapat beberapa hal yang perlu dilakukan perbaikan seperti konsumen menilai Brizzi kurang dalam meningkatkan produktivitas mereka, maka dari itu diharapkan Brizzi perlu 
meningkatkan sistem yang dapat meningkatkan produktivitas pada penggunanya.

Tanggapan pengguna terkait dimensi continuance intention dapat dikatakan cukup baik. Namun, terdapat indikator yang harus diperbaiki yang dapat menjadi ancaman bagi peningkatan continuance intention pada Brizzi seperti pada indikator times of repurchase. Maka dari itu penulis menyarankan perusahaan lebih meningkatkan kebermanfaatan pada produk Brizzi yang dijualnya agar konsumen merasa tidak ragu untuk menggunakan kembali Brizzi dalam frekuensi yang sering.

Hasil penelitian ini menyatakan bahwa perceived usefulness berpengaruh dalam peningkatan continuance intention penggunaan Brizzi BRI di Indonesia, maka dari itu penulis merekomendasikan agar perusahaan dapat meningkatkan indikator work more quickly, job performance, increase productivity, effectiveness, makes job easier, dan useful. Penelitian ini diharapkan dapat menjadi dasar atas dilakukannya penelitian lain terkait continuance intention tetapi dengan indikator yang berbeda di masa yang akan datang.

\section{DAFTAR PUSTAKA}

Alsabawy, A. Y., Cater-Steel, A., \& Soar, J. (2016). Determinants of perceived usefulness of elearning systems. Computers in Human Behavior, 64 843-858. http://doi.org/10.1016/j.chb.2016.07.065

Al-Suqri, M. N. (2014). Perceived usefulness, perceived ease-of-use and faculty acceptance of electronic books: An empirical investigation of Sultan Qaboos University, Oman. Library Review, 63(4-5), 276-294. http://doi.org/10.1108/LR-052013-0062

Bangkara, R. P., Putu, N., \& Harta, S. (2016). E-Jurnal Akuntansi Universitas Udayana Pengaruh Perceived Usefulness dan Perceived Ease of Use pada Minat Penggunaan Internet Banking dengan Attitude Toward Using Sebagai Variabel Intervening Fakultas Ekonomi dan Bisnis Universitas Udayana , Bali , Indone, 16, 24082434. Retrieved from ISSN: 2302-8556

Bhattacherjee, A. (2015). An empirical analysis of the antecedents of electronic commerce service continuance, 32, 201-214.
Chang, Y. P., \& Zhu, D. H. (2012). The role of perceived social capital and flow experience in building users ' continuance intention to social networking sites in China, 28, 995-1001. http://doi.org/10.1016/j.chb.2012.01.001

Chen, I. Y. L. (2015). The factors influencing members , continuance intentions in professional virtualcommunities - a longitudinal study, (X), 117. http://doi.org/10.1177/0165551506075323

Davis, F. D. (1989). Perceived Usefulness, Perceived Ease Of Use, and User Acceptance of Information Technology.

Erisha, M., \& Razati, G. (2016). Pengaruh Kinerja People Dan Physical Evidence Terhadap Keputusan Menginap ( Survei Terhadap Tamu Hotel Kampung Sumber Alam Garut ), 1(2), 1724.

Gao, L., \& Bai, X. (2014). An empirical study on continuance intention of mobile social networking services: Integrating the IS success model, network externalities and flow theory. Asia Pacific Journal of Marketing and Logistics, 26(2), 168189. http://doi.org/10.1108/APJML-07-2013$\underline{0086 .}$

Hasibuan, Z. A. (2007). Metodologi Penelitian Pada Bidang Ilmu Komputer Dan Teknologi Informasi. Depok: Modul Perkuliahan Metodologi Penelitian pada Bidang Ilmu Komputer dan Teknologi Informasi Universitas Indonesia.

Hu, J., \& Zhang, Y. (2016). Understanding Chinese Undergraduates' Continuance Intention to Use Mobile Book-Reading Apps: An Integrated Model and Empirical Study. Libri, 66(2), 85-99. http://doi.org/10.1515/libri-2015-0090

Hou, H. B. B. L. J. S. F. (2016). Repurchase Intention in Chinese E-marketplace : Roles of Interactivity, Trust and Perceived Effectiveness of E-commerce Institutional Mechanisms, 116(8), -. Retrieved from http://dx.doi.org/10.1108/IMDS-07-20150296

Ju, Y., Park, S., \& Kyoung, E. (2017). Computers in Human Behavior Students, expectation, satisfaction, and continuance intention to use digital textbooks. Computers in Human Behavior, 69, 83-90. http://doi.org/10.1016/j.chb.2016.12.025

Kuntjojo. (2009). Metodologi Penelitian. Modul Perkuliahan Metodologi Penelitian.

Kotler, \& Keller. (2016). Marketing Management (15th ed.). Global Edition.

Lee, Y., \& Kwon, O. (2011). Electronic Commerce Research and Applications Intimacy, familiarity and continuance intention: An extended expectation - confirmation model in web-based services, $\quad 10, \quad 342-357$. http://doi.org/10.1016/j.elerap.2010.11.005 
Lwoga, E. T., \& Komba, M. (2015). Antecedents of continued usage intentions of web-based learning management system in Tanzania, 57(7), 738-756. http://doi.org/10.1108/ET-02-2014-0014

Maholtra, K. N. (2010). Marketing Reseach: An Applied Orientation Sixth Ed Pearson Education (Sixth edit). Pearson Education.

Mouakket, S., \& Bettayeb, M. A. (2015). Investigating the factors influencing continuance usage intention of Learning management systems by university instructors The Blackboard system case, 11(4), 491-509. http://doi.org/10.1108/IJWIS-03-2015-0008

Noorhidawati, A., \& Ghalebandi, S. G. (2016). Continuance intention of using e- book among higher education students, 2l(1), 19-33.

Razati, G., \& Ruhimat, R. (28). Pengaruh Sales Promotion Terhadap Keputusan Menggunakan Kartu Kredit BNI. Jurnal Pendidikan Manajemen Bisnis, 1-15.

Susanto, A., Young, C., \& Ha, Y. (2016). Determinants of continuance intention to use the smartphone banking services An extension to the, 116(3), 508-525. http://doi.org/10.1108/IMDS-05-2015019.

Segars, A. H., \& Grover, V. (2015). Re-examining perceived ease of use and usefulness.

Solomon. (2007a). Consumer Behaviour: A European Perspective. Pharmacy world \& science: PWS (Vol. 29). http://doi.org/10.1007/s11096-0053797-z

Yeh, R. K.-J., \& Teng, J. T. C. (2012). Extended conceptualisation of perceived usefulness: empirical test in the context of information system use continuance. Behaviour \& Information Technology, 31(5), 525-540. http://doi.org/10.1080/0144929X.2010.517272

Zhang. (2017). How Wechat Can Retain Users: Roles Of Network Exterbalities, Social Interaction Ties, Adn Perceived Values In Building Continuance Intention.

http://doi.org/10.1016/j.chb.2016.11.069 